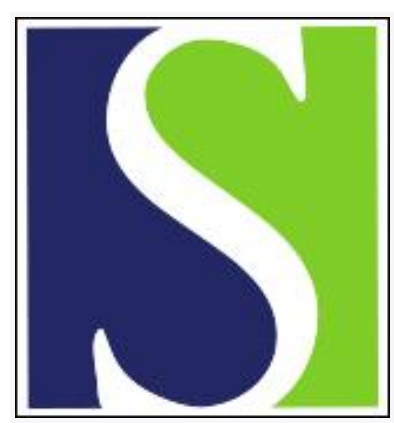

Scand J Work Environ Health 1984;10(5):311-316

https://doi.org/10.5271/sjweh.2328

Issue date: Oct 1984

Effect of cohort definition and follow-up length on occupational mortality rates.

by Koskela RS, Jarvinen E, Kolari PJ

This article in PubMed: www.ncbi.nlm.nih.gov/pubmed/6335294

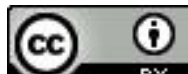




\title{
Effect of cohort definition and follow-up length on occupational mortality rates ${ }^{1}$
}

\author{
by Riitta-Sisko Koskela, MSocSc, Erkki Järvinen, MSc, Pertti J Kolari, MSc ${ }^{2}$
}

\begin{abstract}
KOSKELA R-S, JÄRVINEN E, KOLARI PJ. Effect of definition of a cohort and length of follow-up on occupational mortality rates. Scand $J$ Work Environ Health 10 (1984) 311-316. The purpose of this study was to clarify the effects of cohort formation, period of entry, and period of follow-up on occupational mortality figures. The study material comprised three cohorts of metal industry workers $(6415$ iron foundry workers, 3901 metal product workers, and 5398 workers manufacturing electrical devices). The men, hired between 1950 and 1976, were followed until the end of 1978. The number of person-years was approximately 215800 . Different cohort formation criteria and variations in the follow-up modify the results of occupational mortality studies. A cross-sectionally based cohort (workers employed in a certain year or years) produces results different from those for an open cohort (new workers hired during a certain period of time) although the cohorts are formed from the same workplaces. The cohorts for retrospective cohort studies usually contain various periods of entry, periods of follow-up, and age structures. Increased or decreased mortality in a cohort depends on this internal structure. The structure of the cohort becomes especially important when a certain cause of death is concentrated in certain age classes and/or when a period of latency is required, as for tumors. In an attempt to reveal this internal structure the three cohorts were analyzed in five-year calendar periods and stratified according to the length of follow-up. The mortality pattern remained nearly unchanged when the number of periods of entry increased, and it was also comparable with the mortality pattern of the general male population. But as the period of follow-up grew longer, the mortality pattern changed, partly due to the ageing of the cohort and partly due to increasing periods of exposure and latency. A cohort of Finnish granite workers was used for testing the stratified analysis.
\end{abstract}

Key terms: cancer mortality, cross-sectional cohort, epidemiologic methods, granite workers, health selection, metal industry, open cohort.

Different cohort formation criteria and variations in follow-up modify the results of occupational mortality studies $(2,4)$. A cross-sectionally based cohort (workers employed in a certain year or years) will produce results that differ from those of an open cohort (new workers hired during a certain period of time) even if the cohorts have been formed from the same workplaces. The former cohort is affected, like cross-sectional study designs in general, by health selection, and the latter is liable to weaken the possible effects of exposure, especially in occupations with rapid turnover. Even if the direction of the results in the designs were the same, the total mortality rates may vary and may cause differences in cause-specific figures $(3,4,7)$.

\footnotetext{
1 Part of the text has been presented at the International Symposium on Research on Work-Related Diseases, 4-8 June 1984, Espoo, Finland, and part of the XXI International Congress on Occupational Health, 9-14 September 1984, Dublin, Ireland.

2 Department of Epidemiology and Biometry, Institute of Occupational Health, Helsinki, Finland.
}

Reprint requests to: Ms R-S Koskela, Institute of Occupational Health, Haartmaninkatu 1, SF-00290 Helsinki, Finland.
The length of the period of entry similarly causes variations in mortality rates. In addition, restriction of the cohort, sampling, and orientation towards, eg, certain age groups, matching, or the requirement of a minimum length of exposure, modify the results of occupational mortality studies $(2,3,4,5)$.

The purpose of the present study was to clarify the effects of cohort formation, period of entry, and period of follow-up on occupational mortality figures.

\section{Materials and methods}

The study material comprised three cohorts of metal industry workers (6 415 iron foundry workers, 3901 metal product workers, and 5398 workers manufacturing electrical devices). The men, hired between 1950 and 1976, were followed until the end of 1978. The number of person-years was approximately 215800 . During the period $1950-1978$, there were 1407 deaths. In addition another methodological (cross-sectional) cohort was comprised of 1526 workers who had been hired earlier and were still working in 1950 . The basic information was collected from the employers' records. Data for the analysis of 
Table 1. Standardized mortality ratios (SMR) for cross-sectionally based (workers at work in 1950 but hired earlier) and open cohorts (workers who had entered the industries in 1950-1976).

\begin{tabular}{|c|c|c|c|c|c|c|}
\hline \multirow{3}{*}{ Cause of death } & \multicolumn{6}{|c|}{ Industry } \\
\hline & \multicolumn{2}{|c|}{ Foundry } & \multicolumn{2}{|c|}{ Metal products } & \multicolumn{2}{|c|}{ Electrical devices } \\
\hline & $<1950$ & $\geq 1950$ & $<1950$ & $\geq 1950$ & $<1950$ & $\geq 1950$ \\
\hline $\begin{array}{l}\text { All deaths } \\
\text { Violent deaths } \\
\text { Respiratory diseases } \\
\text { Cardiovascular diseases } \\
\text { Tumors }\end{array}$ & $\begin{array}{r}87^{*} \\
96 \\
109 \\
87 \\
98\end{array}$ & $\begin{array}{l}127^{*} \\
170^{* *} \\
162^{* *} \\
111 \\
85\end{array}$ & $\begin{array}{l}83^{*} \\
97 \\
57 \\
79^{*} \\
91\end{array}$ & $\begin{array}{r}95 \\
110 \\
88 \\
98 \\
86\end{array}$ & $\begin{array}{c}147^{\star} \\
60^{\mathrm{a}} \\
222^{\mathrm{a}} \\
128 \\
60\end{array}$ & $\begin{array}{l}110 \\
129^{*} \\
92 \\
94 \\
95\end{array}$ \\
\hline
\end{tabular}

* $p<0.05,{ }^{* *} p<0.01$; test of significance for the null hypothesis of SMR $=100$ based on the Poisson distribution.

a Based on only four subjects.

\section{Cumulative incidence}
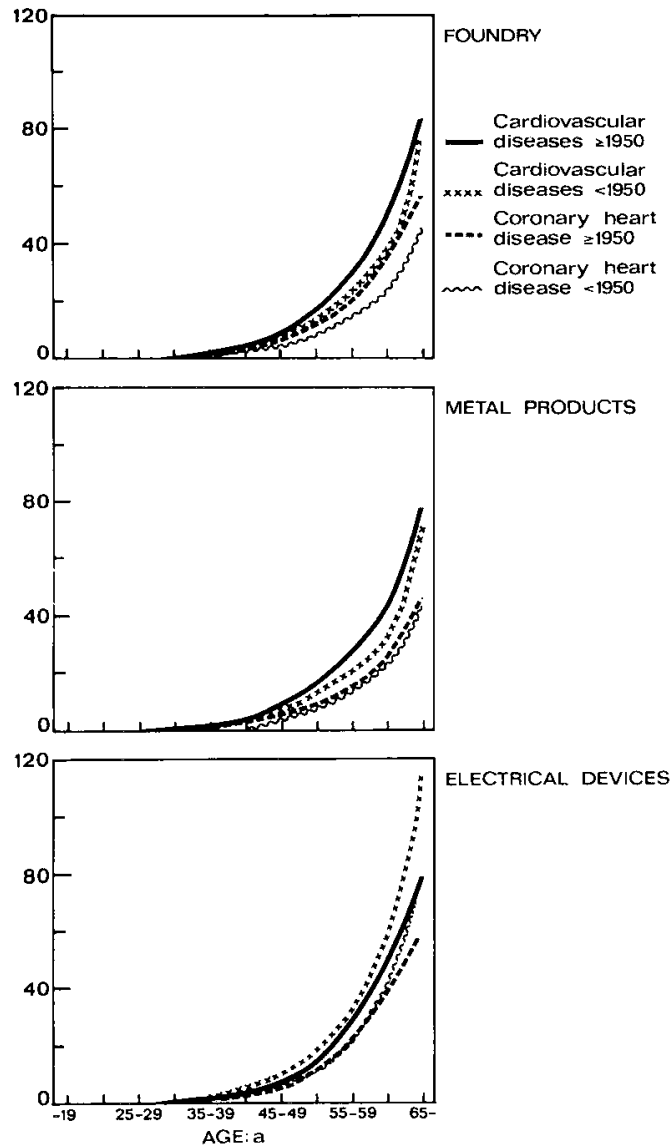

Figure 1. Mortality from all cardiovascular diseases and coronary heart disease. Comparison of the workers who entered the industries in 1950-1976 and those who entered earlier but were still at work in 1950 .

mortality were obtained from the national death register. The official statistics on causes of death in 1970 were selected for comparison with the general male population in the analysis of the open cohorts (hired between 1950 and 1976), and the official statistics for 1965 were used in the analysis of the crosssectional cohorts (still at work in 1950 but hired earlier). These years were chosen on the basis of the median year of the deaths in the cohorts. The material was also stratified according to the periods of entry and follow-up. Then the period-specific mortality figures of the total male population were used to calculate the expected number of deaths.

When the cohorts and the subcohorts were compared with the general male population, the standardized mortality ratio was computed according to the cause of death. Because the age structure of the cohorts, and also of the subcohorts, did not essentially deviate from each other, the method yielded results analogous to the comparison of incidences between the cohorts.

\section{Results}

Comparison of the cross-sectionally based and open cohorts

Comparison of the cross-sectional and open cohorts produced different mortality patterns. The cross-sectional cohorts had lower standardized mortality ratios than the open cohorts, which thus were highly selected groups (table 1). Health selection during employment was indicated, eg, by the results for mortality from all cardiovascular diseases combined and from coronary heart disease separately (figure 1). The younger cohort of foundry workers had a higher mortality from cardiovascular diseases than the older cohort. The difference occurred mainly in the mortality from coronary heart disease. A similar difference was found for the cohorts of the metal product workers, but coronary heart disease did not explain this difference. The electrical workers, however, had an opposite model. The older cohort had higher cumulative incidences than the younger one. This result suggests that the electrical workers' health selection during employment was low.

\section{Variations in time-specific rates}

The standardized mortality ratios of the cohorts clearly depended on whether they were calculated as period-specific or cumulative or according to years since entry (figure 2). Thus, if the study had been 

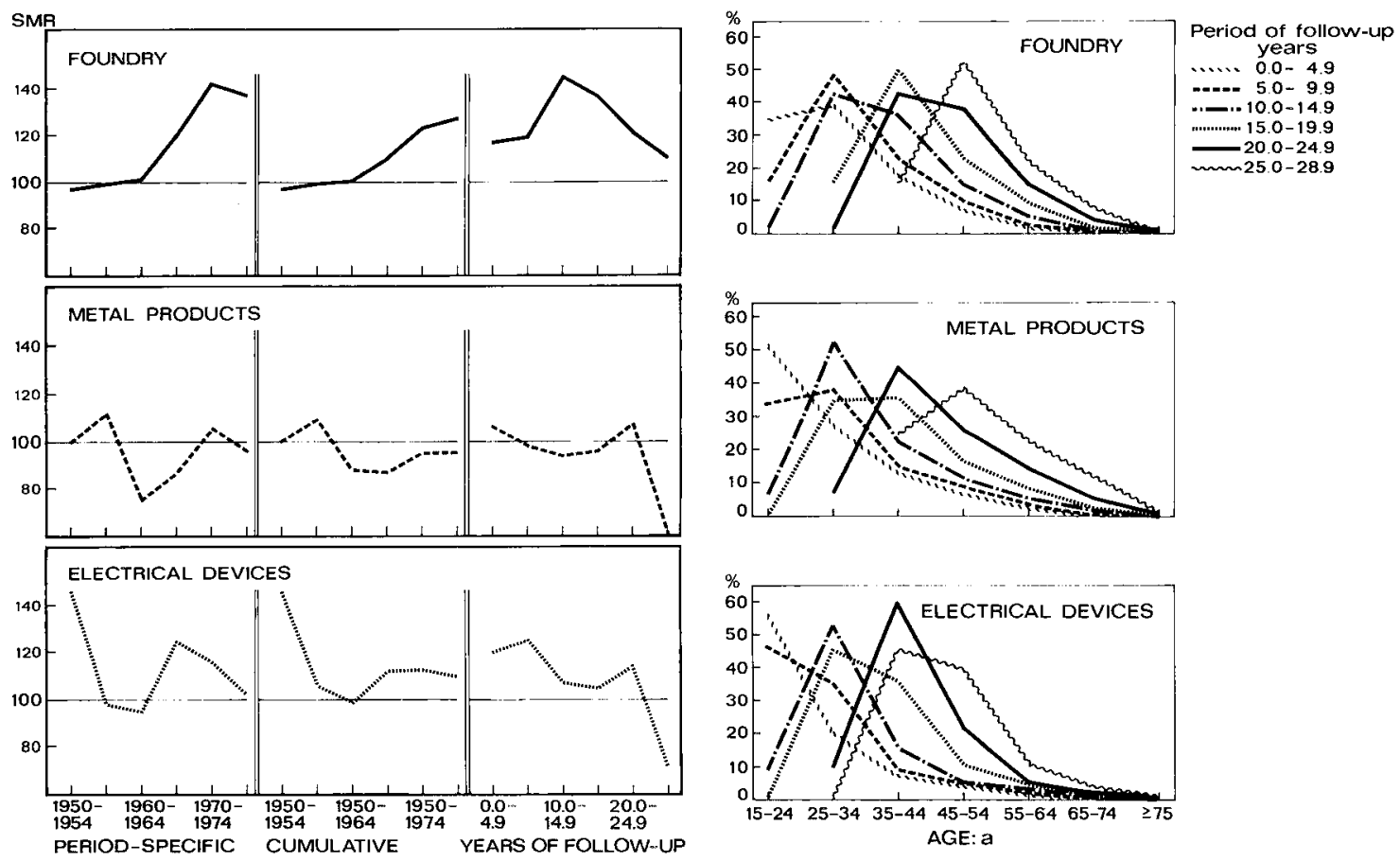

Figure 2. Standardized mortality ratios (SMR) for the three cohorts (including workers hired between 1950 and 1974 and followed until 31 December 1978) calculated according to calendar time as period-specific and cumulative ratios and according to the number of years since entry.

done at some other time or if the data had been analyzed in some other way, the results would also have been somewhat different. Calculation of the results for the periods since entry showed the ageing of the cohorts, whereas calculation for the calendar periods showed the same or somewhat younger age structure of the cohorts as the number of periods of entry increased (figures $3 \& 4$ ).

Changes in age structure also mean changes in mortality pattern (figure 5). The proportions of violent deaths, deaths from cardiovascular diseases, and tumors per age class varied according to the period of entry and the period of follow-up (years since entry). The mortality pattern remained nearly unchanged when the number of periods of entry increased, and it was also comparable with the mortality pattern of the general male population. But as the period of follow-up grew longer, the mortality pattern changed, partly due to the ageing of the cohort and partly due to increasing periods of exposure and latency.

\section{Internal structure of cohorts}

The cohorts for retrospective cohort studies usually contain various periods of entry, periods of followup, and age structure (figure 6). In an attempt to reveal this internal structure, the three open cohorts were analyzed in five-year calendar periods and stra-

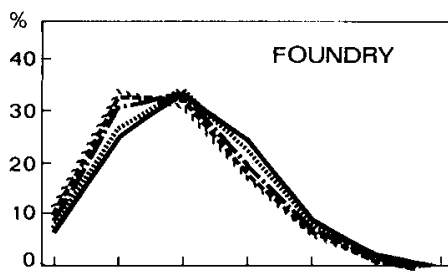

gure 3. Distribution of person-years for according to age and period of follow-up.
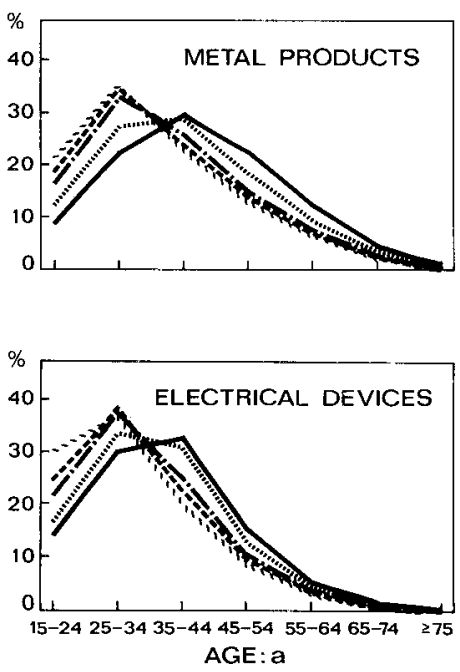

Figure 4. Distribution of person-years for the three cohorts according to age and period of entry. 
$\%$ PERIOD OF FOLLOW-UP

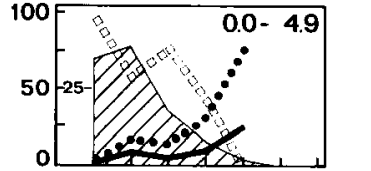

$10055.0-9.9$
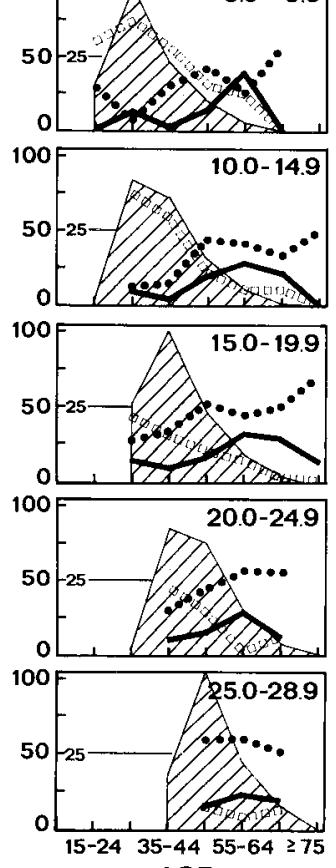

AGE: a

เин:1 Violent deaths

..... Cardiovascular diseases

- Tumors

- Person-years

Figure 5. Proportions of violent deaths, deaths from cardiovascular diseases, and tumors per age class and the distribution of person-years in the cohort of foundry workers according to period of follow-up. The corresponding distributions of the general male population are presented for comparison.
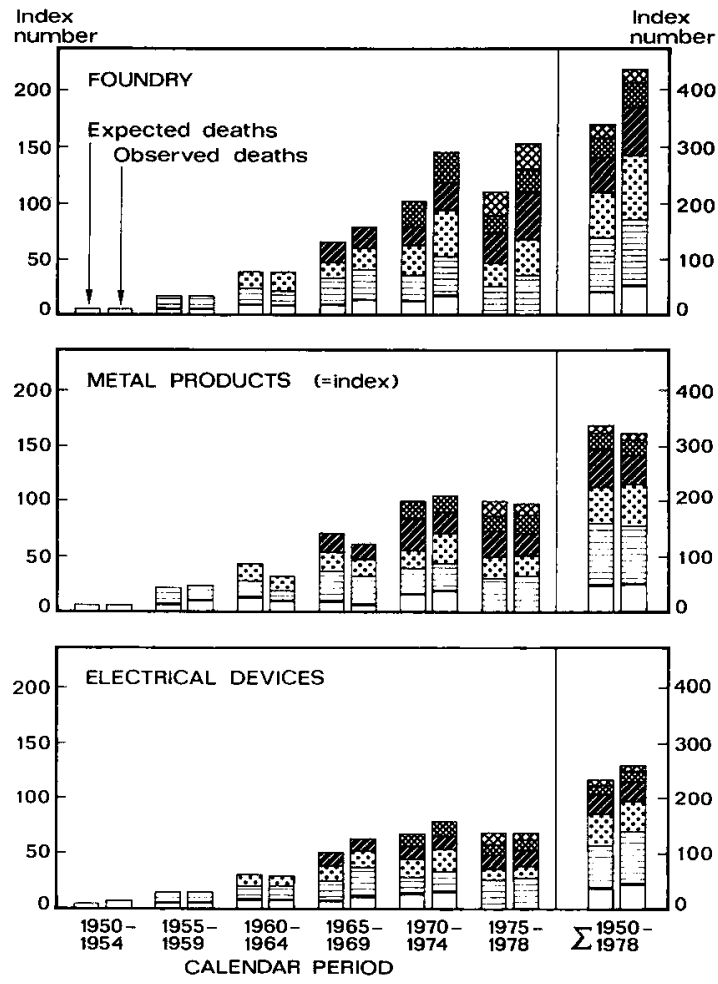

PERIOD OF FOLLOW-UP, yearS

$\begin{array}{rr}0.0-4.9 & 15.0-19.9 \\ 5.0-9.9 & 20.0-24.9 \\ 10.0-14.9 & 25.0-28.9\end{array}$

Figure 6. Expected and observed perlod-specific deaths in the three cohorts stratified according to the length of followup. The expected numbers were stratified according to the percentage distribution of person-years in each calendar period. The observed numbers were stratified according to the percentage distribution of person-years weighted by standardized mortality ratio for the specific period of follow-up. The figures are expressed as index numbers (the expected numbers in each calendar period among metal product workers $=100$ ).

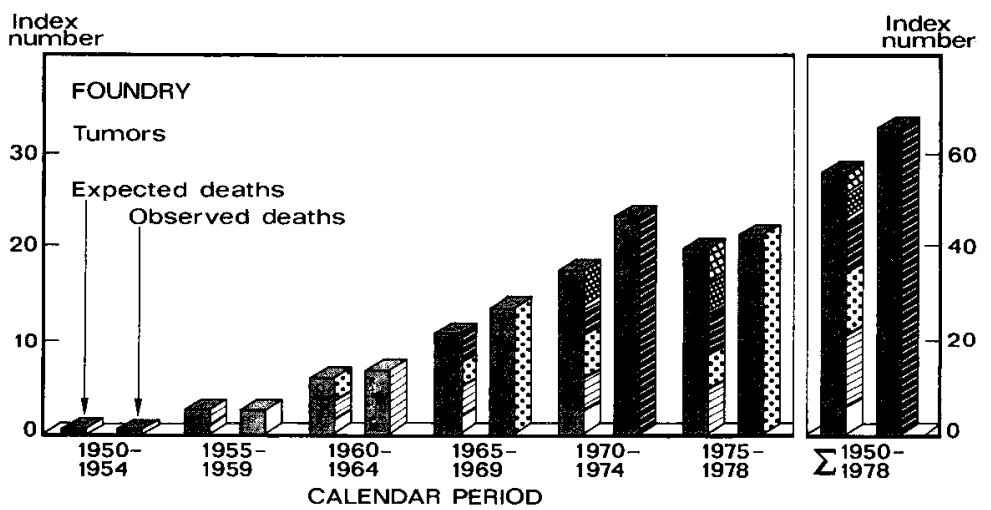

PERIOD OF FOLLOW-UP, yearS

$0.0-4.9$
$5.0-9.9$
$10.0-14.9$
$20.0-24.9$
$25.0-28.9$
Figure 7. Mortality from tumors among foundry workers according to calendar periods. The expected numbers were stratified into the periods of follow-up (as in figure 6). The observed numbers are designated with a sym. bol for the period of follow-up that produced the highest standardized mortality ratio. (Calculation of the index numbers is presented in figure 6). 
tified according to the length of follow-up. The period-specific mortality figures of the total male population were used to calculate the expected number of deaths. The expected numbers were divided into different follow-up periods according to the percentage distribution of person-years in each calendar period. The observed numbers were divided according to the percentage distribution of personyears weighted by the standardized mortality ratio (based on age-specific figures) for a specific period of follow-up. The figures were transformed into index numbers with the calendar period-specific expected numbers of the metal product workers as indices.

Increased or decreased mortality in a cohort depends on the internal structure of the cohort. The structure of the cohort becomes especially important when a certain cause of death is concentrated in certain age classes and/or when a period of latency is required, as for tumors. The importance of cohort structure was verified in the cohort of foundry workers (a cohort with cancer risk) (figure 7). According to calendar periods mortality from tumors was not excessive until the internal structure of the cohort contained at least ten-year periods of followup. In this context the expected numbers were calculated in the same way as for all causes of death. The follow-up period for which the highest standardized mortality ratio was detected was used to indicate the observed number in each calendar period and thus was designated with only one symbol. The clearest excess mortality from tumors was found in the calendar period of 1970 to 1974 and was located in a 15to 20 -year follow-up period. The observed numbers were no longer excessive in the next follow-up period.

The clearest evidence of excess mortality from tumors was detected when the optimum composition coefficient prevailed for both the age structure (4564 years) and the latency period ( $15-20$ years). The period of entry then was 1950 to 1964 , the calendar period 1970 to 1974 . It is worth noting that excessive mortality from tumors thereafter decreased considerably (figure 8 ).

\section{Adaptation of the optimum composition method}

Many epidemiologic cohort studies are methodologically insufficient to reveal occupational mortality, especially from cancer. This lack has surfaced in cohorts that have been followed up several times. One example is a cohort of Finnish granite workers. The cohort comprised 1086 granite workers hired between 1940 and 1971 and followed up three times - until the end of 1972, 1975, and 1981 (1). The first follow-up indicated slightly higher mortality from respiratory diseases and from cancer of digestive organs, but the findings were not statistically significant. The second follow-up then clearly confirmed an excess mortality from both types of diseases. Increasing mortality from lung cancer was revealed by the third follow-up (table 2).
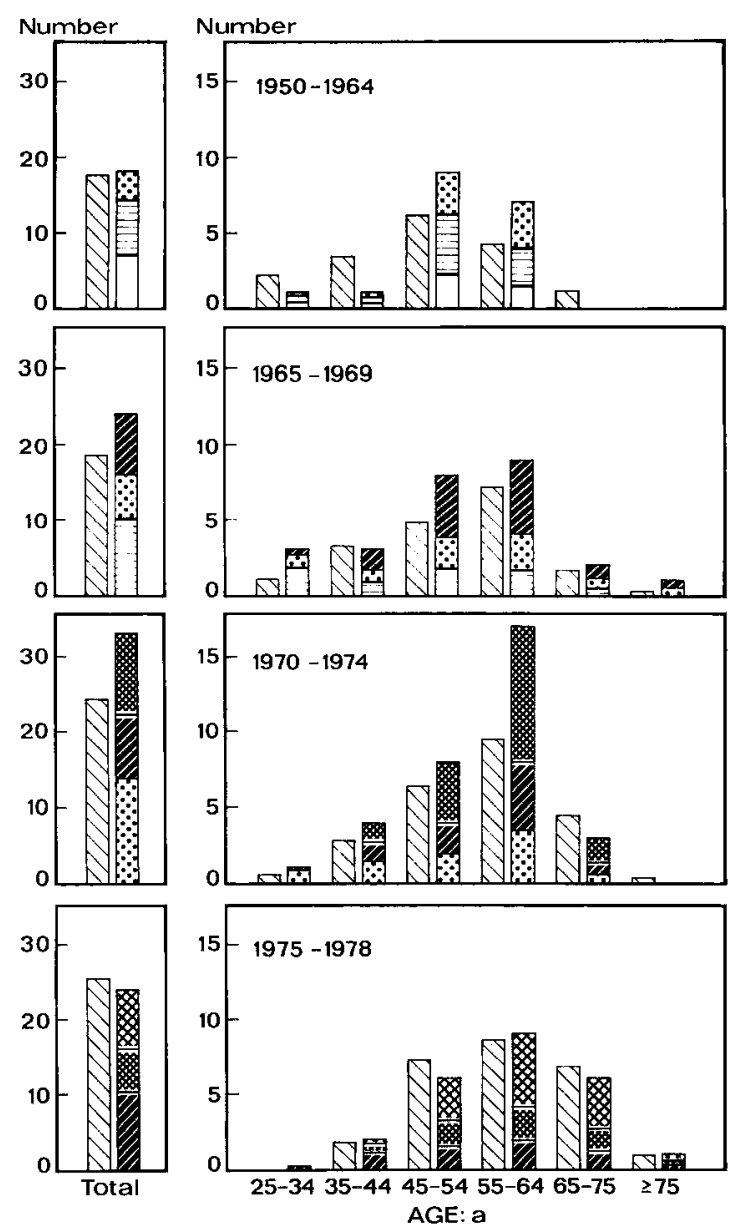

OBSERVED TUMORS:

EXPECTED TUMORS:

Period of follow-up, years

$\begin{array}{rl}\square & 0.0-4.9 \\ 5.0-9.9 & 15.0-19.9 \\ 20.0-24.9 & 25.0-28.9\end{array} \quad \square$ Total number

Figure 8. Age-specific expected and observed numbers of tumors in a closed cohort of foundry workers hired between 1950 and 1964 and followed until 31 December 1978. The observed numbers were stratified according to the percentage distribution of person-years in a specific age class.

Table 2. Standardized mortality ratios (SMR) for the cohort of granite workers at the end of the years of follow-up. The period of entry was defined from 1950 to 1971.

\begin{tabular}{lccc}
\hline Cause of death & 1972 & 1975 & 1981 \\
\hline Cardiovascular diseases & $71^{*}$ & $70^{*}$ & 80 \\
Tumors & 86 & 100 & 92 \\
Lung cancer & $44^{\mathrm{a}}$ & 74 & 112 \\
Cancer of digestive organs & 185 & $203^{*}$ & 130 \\
Respiratory diseases & 200 & $265^{* *}$ & $174^{* *}$ \\
\hline Total & 91 & 94 & 93 \\
\hline
\end{tabular}

* $p<0.05, * a<0.01$; test of significance for the null hypothesis of SMR $=100$ based on the Poisson distribution.

a Based on only four subjects. 


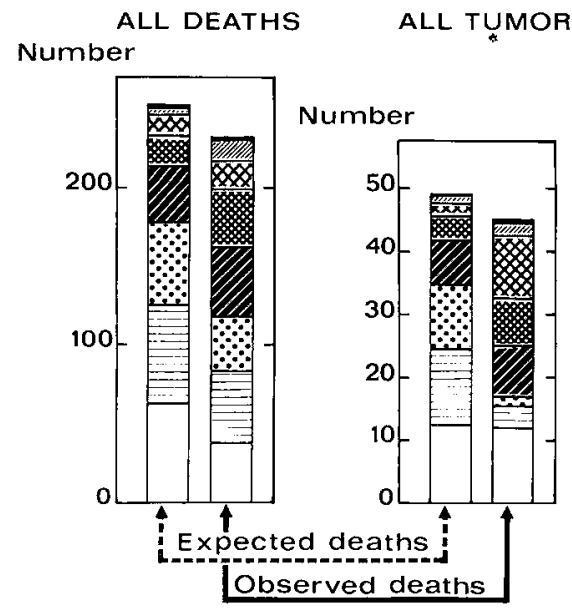

PERIOD OF FOLLOW-UP, years

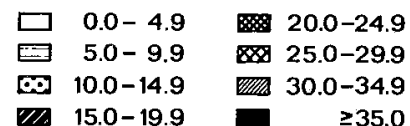

Figure 9. Overall mortality and mortality from tumors among granite workers hired between 1940 and 1971 and followed until 31 December 1981. The expected and observed numbers were stratified into periods of follow-up (as in figure 6).

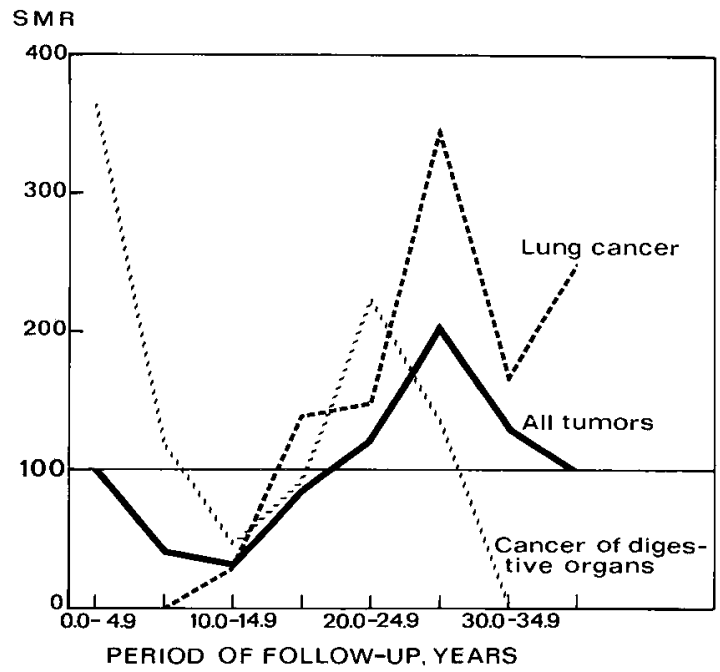

Figure 10. Mortality from tumors in the cohort of granite workers from 1940 to 1981 . Standardized mortality ratios (SMR) for all tumors, lung cancer, and cancer of digestive organs according to years of follow-up.

The internal structure of the cohort showed that excess overall mortality did not become evident until the granite workers had been followed up at least 20 years, but in 1981 only $15 \%$ of the granite workers could be followed for so long (figure 9). This finding reveals that potential excess mortality from a certain disease can be hidden in the internal structure of the cohort and can be detected by stratification of the material according to periods of entry, periods of follow-up, and age structure.

Even though excess mortality from tumors was not incontestably detected in the whole cohort of granite workers, it was clear in the group of workers followed up for 20 years or more. The greatest excess was found for the latency period of 25 to 29 years. The excess was mainly caused by lung cancer (figure $10)$.

\section{Conclusion}

Discrepancies between different mortality studies in the same occupational groups may be caused by different criteria for cohort formation and by variations in follow-up. To detect the optimum composition of the cohort to reveal potential excess mortality from a certain disease, the age distribution of person-years in different periods of follow-up and the percentage of different periods of follow-up in a certain age class are needed, in addition to age-specific occurrences of the disease. The optimum composition of the cohort varies according to exposure and period of latency. It is also affected by various confounding factors in different occupational cohorts, as well as by turnover rates. However, stratified analysis is a tool that can be used to point out the informativeness of the cohort study at a certain time.

\section{References}

1. Ahlman K, Backman A-L, Hannunkari I, Järvinen E, Koponen M, Koskela R-S, Partanen T, Seppäläinen AM, Starck J. Kivityöntekijöiden työolosuhteet ja terveydentila [Work conditions and health of granite workers]. The Social Insurance Institution, Helsinki 1975. $128 \mathrm{p}$. (Kansaneläkelaitoksen julkaisuja AL: 4/1975).

2. Enterline PE. Pitfalls in epidemiological research. J Occup Med 18 (1976) 150-156.

3. Fox AJ, Collier PF. Low mortality rates in industrial cohort studies due to selection for work and survival in the industry. Br J Prev Soc Med 3 (1976) 225-230.

4. Mancuso TF, El-Attar AA. Dynamic changes in in dustrial cohort studies. Ind Med Surg 35 (1966) 10591067.

5. McMichael AJ. Standardized mortality ratios and the "healthy worker effect": Scratching beneath the surface. J Occup Med 18 (1976) 165-168.

6. Monson RR. Occupational epidemiology. CRC Press, Poca Raton, FL 1980.

7. Weiss W. Heterogeneity in historical cohort studies: A source of bias in assessing lung cancer risk. J Occup Med 25 (1983) 290-294.

Received for publication: 1 July 1984 